\title{
Concepções de gênero e violência contra a mulher
}

\section{Gender conceptions and violence against women}

\section{Concepciones de género y violencia contra la mujer}

\author{
Júnnia Maria Moreira 1, ORCID 0000-0003-1167-111X \\ Hellen Luane Silva Peixinho ${ }^{2}$, ORCID 0000-0002-9210-6675 \\ Gleice de Oliveira Cordeiro ${ }^{3}$, ORCID 0000-0003-0273-5126 \\ Jackeline Maria de Souza ${ }^{4}$, ORCID 0000-0003-3402-3481 \\ ${ }^{12}$ Universidade Federal do Vale do São Francisco - UNIVASF - Brasil \\ ${ }^{3}$ Universidade Estadual de Feira de Santana. Brasil \\ ${ }^{4}$ Universidade de São Paulo - USP - Brasil
}

\begin{abstract}
Resumo: Comportamentos violentos contra a mulher podem ser aprendidos por meio de regras. A presente pesquisa avaliou o nível de concordância com regras descritivas relativas a concepções de gênero e violência contra a mulher em uma amostra de 49 profissionais da assistência social e segurança pública alocados em dois grupos: com e sem treinamento sobre violência doméstica. Foram aplicados questionários em que o participante avaliava o seu nível de concordância em relação a 35 itens. A variável "treinamento" apontou diferenças significativas apenas na categoria 12 , referente à relação do profissional com a vítima, em que o grupo com treinamento apresentou menor concordância e maior discordância. $\mathrm{O}$ treinamento pode alterar concepções de gênero, porém maiores investigações são necessárias visto que essa alteração ocorreu apenas na categoria referente à atuação profissional. Uma limitação do estudo consistiu em não avaliar outras variáveis como o tipo de treinamento e a escolaridade.
\end{abstract}

Palavras-chave: violência contra a mulher; concepções de gênero; regras descritivas; treinamento de profissionais; análise do comportamento

Abstract: Violent behaviors against women can be learned, among other forms, through rules. The present study evaluated the level of agreement with descriptive rules related to gender conceptions and violence against women in a sample of 49 social work and public safety professionals divided in two groups: with and without training on domestic violence. Questionnaires were applied, in which the participant evaluated their level of agreement regarding 35 statements. The "training" variable showed significant differences only in category 12 , regarding the relationship between the professional and the victim, in which the group with training presented less agreement and greater disagreement. Training can change gender conceptions, but further investigations are necessary since this change occurred only in the category related to professional performance. One limitation of the study was not to evaluate other variables such as training type and instruction level.

Keywords: violence against women; gender conceptions; descriptive rules; professional training; behavior analysis 
Resumen: Las conductas violentas contra la mujer pueden ser aprendidas por medio de reglas. La presente investigación evaluó la concordancia con reglas descriptivas relativas a concepciones de género y a violencia contra la mujer en una muestra de 49 profesionales de la asistencia social y seguridad pública asignados en dos grupos: con y sin entrenamiento en violencia doméstica. Se aplicaron cuestionarios en los que el participante evaluaba su nivel de concordancia con 35 afirmaciones. La variable "entrenamiento" apuntó diferencias significativas sólo en la categoría 12, referente a la relación del profesional con la víctima, en que el grupo con entrenamiento presentó menor concordancia y mayor discordancia. El entrenamiento puede cambiar las concepciones de género, pero son necesarias más investigaciones, ya que este cambio se produjo solo en la categoría relacionada con el desempeño profesional. Una limitación del estudio consistió en no evaluar otras variables como el tipo de entrenamiento y la escolaridad.

Palabras clave: violencia contra la mujer; concepciones de género; reglas descriptivas; entrenamiento de profesionales; análisis de la conducta

Como citar:

Moreira, J.M., Peixinho, H.L.S., Cordeiro, G. O., \& Souza, J.M. (2020). Concepções de gênero e violência contra a mulher. Ciencias Psicológicas, 14(2), e-2309. doi: https://doi.org/10.22235/cp.v14i2.2309

Correspondência: Júnnia Maria Moreira. Universidade Federal do Vale do São Francisco - UNIVASF. Colegiado de Psicologia, UNIVASF Campus Petrolina Centro. Avenida José de Sá Maniçoba, S/N, Centro. Petrolina, PE; CEP 56304-91.E-Mail: junnia.moreira@gmail.com. Hellen Luane Silva Peixinho; e-mail: hellenpeixinho23@gmail.com. Gleice de Oliveira Cordeiro; e-mail: gocordeiro@uefs.br. Jackeline Maria de Souza; email:jackeline.souzal@gmail.com

Os dados da Organização Mundial da Saúde (2014) revelam que 30\% das mulheres no mundo, que tiveram um relacionamento afetivo, sofreram algum tipo de violência física ou sexual por um parceiro íntimo em algum momento de suas vidas. A despeito da possibilidade de mutualidade na violência conjugal (Rosa \& Falcke, 2014), a mulher ocupa uma posição de maior vulnerabilidade mesmo nessas situações de violência mútua (Barros \& Schraiber, 2017; Lindner, Coelho, Bolsoni, Rojas \& Boing, 2015). Além disso, a violência contra a mulher, especificamente, tem sido alvo de pesquisas e intervenções em função de estatísticas alarmantes, além de não se restringir ao contexto conjugal e acometer todos os níveis de escolaridade, classes sociais e tipos étnicos (Santos, Antunes \& Penna, 2014). No Brasil, segundo o Mapa da violência de 2015 (Waiselfisz, 2015), entre os anos de 2003 e 2013 ocorreu um aumento de 21\% dos homicídios contra o sexo feminino. Isto levou a serem sancionadas a Lei Maria da Penha (Lei 11.340/2006) e a Lei do Feminicídio (Lei 13.104/2015), esta última classificando o feminicídio como crime hediondo e com agravantes quando acontece em situações específicas de vulnerabilidade (gravidez, na presença de filhos, menor de idade, entre outras; ver Taquette, 2015 para uma revisão sobre violência contra a mulher adolescente).

O Instituto de Pesquisa Econômica Aplicada (IPEA) aponta que entre os anos de 2009 e 2011 nos estados da Bahia e de Pernambuco, lócus dessa pesquisa, as taxas de feminicídio foram de 9,08 e 7,81 por 100 mil mulheres, respectivamente (IPEA revela dados, 2013). Levando, recentemente, o município de Juazeiro/BA a implementar a Ronda Maria da Penha, um serviço especializado no atendimento às vítimas de violência doméstica (Operação Ronda Maria da Penha, 
2015; ver também Brigadão, Santos \& Spink, 2016; Cavalcanti, Moreira, Vieira \& Silva, 2015; Sousa, 2014; Tavares, 2016 para exemplos de avaliações de implantação de medidas similares) sendo esta mais uma conquista garantida no que tange ao combate à violência contra a mulher. No entanto, apesar de medidas desse tipo, poucas mudanças foram observadas de fato no quadro da violência contra a mulher no Brasil (Gomes, 2015). Estudos e medidas protetivas em casos de violência contra a mulher tornam-se ainda mais relevantes diante de prejuízos que afetam também a saúde física das vítimas (Coronel \& Silva, 2018).

A violência contra a mulher é definida como qualquer ato de violência, baseada no gênero, que venha a causar dano sexual, físico, psicológico, patrimonial, dentre outros, praticado por pessoas ou instituições (Brasil, 2011; Organização Mundial da Saúde, 2014; Silva, Sousa \& Borges, 2015). Já o conceito de gênero, refere-se a um conjunto de padrões de comportamento que são considerados típicos de mulheres e de homens num determinado espaço de tempo na história e cultura dos indivíduos (Sant'Ana, 2003; Silva \& Laurenti, 2016). Desta forma, ao se mencionar a violência de gênero, fala-se de uma violência que é derivada de uma organização social em que as práticas culturais favorecem os homens em detrimento das mulheres, isto é, uma organização social patriarcal (Saffioti, 2001; Scott, 1986; Silva \& Laurenti, 2016). Em termos analíticocomportamentais, falar sobre práticas culturais relativas ao gênero é falar sobre formas de controle social, de poder e dominância, que interferem no acesso de um indivíduo ou grupo de indivíduos a fontes de reforçadores dentro de uma cultura (Ruiz, 2003).

Dentre as formas de violência contra a mulher, existe aquela que é praticada especificamente em locais de prestação de serviços, denominada violência institucional. Esta é definida como um tipo de violência que é emitida por um determinado profissional pertencente a uma instituição que assume uma postura na qual utiliza do seu poder de conhecimento como forma de deslegitimar o saber das(os) usuárias(os) do serviço (Aguiar \& D’Oliveira, 2010). Isso acaba por distanciar o profissional do público a ser assistido e impossibilita uma melhor compreensão acerca da realidade social e cultural do sujeito que necessita do serviço (Pedrosa \& Spink, 2011).

O fenômeno da violência é compreendido na análise do comportamento como sinônimo de coerção, sendo definido como o uso da punição e da ameaça de punição para conseguir que os outros ajam da maneira que se deseja e para reforçar um comportamento com a retirada do estímulo aversivo (Sidman, 1989/2003). Um tipo de controle baseado no uso de estímulos aversivos, por exemplo, no âmbito institucional, é quando o(a) profissional intimida a usuária ao avaliar moralmente suas vestes ou itens pessoais (e.g. batom ou maquiagem), dizendo: "A mulher que usa roupas provocativas não pode reclamar se for estuprada". Nesse caso, utiliza-se um estímulo aversivo, a crítica relacionada a "roupas provocativas", para controlar o comportamento da usuária, dando ao mesmo tempo uma instrução implícita - "Não use essas roupas".

O exemplo acima ilustra, além de uma concepção de gênero do falante, o controle instrucional, uma das formas de se aprender com o outro que se configura a partir do uso do comportamento verbal (Skinner, 1957/1978). No exemplo, a instrução do(a) profissional (emitente) tem uma probabilidade de modificar o comportamento da usuária (ouvinte) de utilizar uma determinada roupa. Ou ainda de evitar que esta insista na denúncia ou mesmo procure o serviço de proteção em outra ocasião de risco, o que pode estar correlacionado com os dados de subnotificação da violência contra a mulher (Invisível aos olhos, 2015).

Dizer que um comportamento foi "controlado" por uma instrução ou regra é dizer que ele está sob controle, principalmente, de um estímulo discriminativo verbal (Baum, 2005/2006). Portanto, a função primordial da regra é a mudança do comportamento do ouvinte, sendo este comportamento verbal ou não-verbal. Assim, a regra é capaz de substituir as contingências naturais por antecedentes verbais. Outra função das instruções é alterar as funções de outros estímulos que evocam comportamentos (Schlinger \& Blakely, 1987). O exemplo de interação entre usuáriaprofissional mencionado anteriormente sugere que uma instrução pode alterar as funções dos 
estímulos em uma contingência de forma a controlar um comportamento não-verbal, alterando a probabilidade do comportamento de usar a "roupa provocativa" em uma próxima oportunidade.

Desta forma, o comportamento que é determinado por uma regra, como, por exemplo, uma instrução fornecida por um agente de segurança pública em uma palestra: "Não é decente (ou seguro) uma mulher sair sozinha nas vias públicas à noite, principalmente com roupas devassas, cabelo solto, pois os homens podem lhes assediar, assaltar ou até estuprar". Isso pode controlar o comportamento das ouvintes em evitar sair à noite, mesmo que jamais sejam violentadas, limitando a liberdade das mulheres (Albuquerque, Mescouto \& Paracampo, 2010).

Além disso, as regras podem, ainda, ser categorizadas em dois tipos: prescritivas e descritivas (Paracampo, Albuquerque, Carvalló \& Torres, 2009). Regras prescritivas, ou explícitas, determinam tanto o comportamento a ser emitido quanto o ouvinte específico, por exemplo, quando uma juíza diz "feche suas pernas firmemente e todos os seus órgãos femininos quando for ameaçada de ser estuprada" (Juíza pergunta a vítima, 2016). Já as regras descritivas, ou implícitas, alvo do presente estudo, não especificam um ouvinte em particular e são ilustradas pela frase: "A mulher que apanha e continua com o parceiro gosta de apanhar".

É possível dizer que as regras podem ser preditoras de comportamentos, logo um interessante objeto de análise. Em um estudo elaborado por Gomes e Costa (2014), as autoras aplicaram questionários contendo 25 sentenças, no modelo de regras descritivas relativas à concepções de gênero e violência contra a mulher. As sentenças foram distribuídas em sete categorias: papel tradicional feminino e masculino, privacidade da relação, modelo de família intacta é o ideal, responsabilidade da vítima, ciúme relacionado ao amor, ciúme relacionado à violência, justificativa para a violência e outros. O estudo teve uma amostra de 252 estudantes, universitários e não universitários, de ambos os sexos. Os resultados apontaram que a escolaridade é uma variável estatisticamente significante no que diz respeito à concordância com essas afirmativas, superando, inclusive a variável gênero, sugerindo que o aumento no nível educacional é um fator relevante no que diz respeito à reversão da violência contra a mulher.

Resultados parecidos foram obtidos na replicação de Gomes e Costa (2014) por Callou, Bastos, Moreira e Souza (2016). Em uma amostra de 223 indivíduos, estudantes universitários e não universitários, de ambos os sexos, foi aplicado o questionário de Gomes e Costa, adaptado pelas autoras, contendo 32 afirmativas separadas em 11 categorias. Sete dessas categorias foram retiradas do estudo original e outras quatro foram elaboradas pelas autoras: atribuição da violência ao caráter/natureza do homem-internalismo, atribuição da violência à educação - aprendizagem, sexualidade feminina em função da masculina, atribuição da violência ao consumo do álcool e maior tolerância à violência quando ocorrida verbalmente. As afirmativas foram desenvolvidas com o intuito de dificultar a identificação das categorias às quais elas pertenciam e tornar menos explícita a concordância ou discordância esperada e reforçada socialmente. Os resultados apontaram correlações fracas e moderadas entre escolaridade e concordância com determinados itens, sendo que não universitários apresentaram maior concordância que universitários. E, assim como no estudo de Gomes e Costa (2014), a variável escolaridade superou a variável gênero quanto à concordância.

Estudos como estes vêm sendo discutidos desde a década de 80 e promovem a aquisição de conhecimento acerca da violência de gênero (Bandeira, 2014). No Brasil, os movimentos feministas começaram a produzir trabalhos e fazer parcerias com o Estado no intuito de implementar políticas públicas e serviços para erradicar a violência contra a mulher (Mapeamento das Delegacias da Mulher no Brasil, 2008; Mota, 2004; Saffioti, 2001). A rede de proteção inclui desde o Conselho Nacional dos Direitos da Mulher, Delegacias Especiais de Defesa da Mulher (DEAM) (Pereira, 2006) até outros serviços como o CRAM (Centro de Referência ao Atendimento à Mulher) e o CREAS (Centro de Referência Especializado de Assistência Social), os quais são espaços de acolhimento/atendimento psicológico e social, orientação e suporte jurídico (Secretaria Especial de Políticas para as Mulheres, 2006). 
Os treinamentos podem ser um recurso fundamental para abordar aspectos comportamentais e ambientais, facilitando a aquisição de habilidades e a compreensão de problemas complexos por parte dos profissionais que trabalham com violência contra a mulher, como é o caso das concepções e relações de gênero. Sabendo que o comportamento modelado por contingências é mais sensível a mudanças que ocorram no ambiente do que o comportamento controlado por regras (Matos, 2001), as formações não podem ser essencialmente instrucionais, devem, pois, agregar métodos vivenciais com o ensino de competências técnicas e interpessoais, as quais têm demonstrado maior eficácia social e efetividade na atuação (Del Prette \& Del Prette, 2011). E ainda, além de fazerem parte da política institucional, os treinamentos também devem ser passíveis de avaliação.

A problemática do atendimento nesses serviços e os desafios provenientes de profissões que trabalham com essa temática estão voltados justamente para uma falta de capacitação, visão naturalizada relativa à violência de gênero, medo de fazer a notificação, o que contribui com que os profissionais tenham dificuldades em identificar esse tipo de violência e, por conseguinte, em acolher, assistir e encaminhar devidamente os casos (Mattos, Ribeiro \& Camargo, 2012). Isso nos leva ao questionamento acerca das concepções de gênero e sobre a violência doméstica que permeiam a atuação dos profissionais em serviços de atenção à mulher. Assim, a presente pesquisa replicou o estudo de Callou et al. (2016) com o objetivo de verificar as diferenças nos níveis de concordância com as regras descritivas relativas a concepções de gênero e violência contra a mulher em dois grupos de profissionais: o primeiro com treinamento específico sobre violência contra a mulher e o segundo grupo sem esse treinamento.

\section{Método}

\section{Tipo de estudo}

O presente estudo é do tipo descritivo, correlacional e transversal.

\section{Participantes}

Participaram do presente estudo 49 profissionais da segurança pública e da assistência social que trabalham, independente do tipo de vínculo, com violência contra a mulher. Essa amostra, do tipo não-probabilística por conveniência, foi composta por 24 homens e 25 mulheres, com idade média de 36,7 anos $(D P=8,59)$, variando entre 20 e 63 anos. Do percentual de participantes que forneceram o estado civil, a maioria se encontra na categoria de casados $(59,6 \%)$, seguidos por solteiros (34\%). No que tange à religião a maioria se declarou católico $(44,2 \%)$. Em relação à orientação sexual, todos os participantes se definiram como heterossexuais. A escolaridade variou entre Ensino Fundamental completo (4,3\%), $2^{\circ}$ Grau completo $(19,2 \%), 3^{\circ}$ Grau incompleto $(27,7 \%), 3^{\circ}$ Grau completo $(38,3 \%)$ e Pós-Graduação $(10,6 \%)$.

A respeito da profissão, a maior categoria foi a de policiais militares $(53,1 \%)$, seguidos de não policiais $(24,5 \%)$. Dentro dessa última encontram-se profissionais como: assistentes sociais, psicólogos, estagiários do curso de direito, advogados, dentre outros. A renda dos participantes variou de até dois salários mínimos $(6,5 \%)$ até acima de quatro salários mínimos $(50 \%)$. Em relação à pergunta acerca do treinamento sobre violência contra a mulher, de um total de 49 participantes, $25(51,02 \%)$ responderam que sim e foram alocados no Grupo Com Treinamento (CT), $24(48,97 \%)$ responderam que não e foram alocados no Grupo Sem Treinamento (ST). Os comentários dos participantes foram identificados no texto com a letra "P" maiúscula e o número do participante, seguidos do grupo entre parênteses (e.g., P30 (ST)).

O grupo representado por profissionais $\mathrm{CT}$ foi composto por participantes com idade média de 38 anos $(D P=7,86)$. O grupo ST, composto por participantes com idade média de 35,5 anos $(D P=9,27)$, foi formado em sua maioria por homens $(62,5 \%)$. Em ambos os grupos houve predomínio de policiais militares, católicos e casados. Contudo, destaca-se que no grupo CT houve 
um maior predomínio de participantes do sexo feminino e com maior escolaridade comparado ao grupo ST. Os dados detalhados de cada grupo podem ser observados na Tabela 1.

Tabela 1

Caracterização da amostra considerando os grupos ST e CT

\begin{tabular}{|c|c|c|c|c|c|}
\hline & & \multicolumn{2}{|c|}{ ST } & \multicolumn{2}{|c|}{ CT } \\
\hline & & $N$ & $\%$ & $N$ & $\%$ \\
\hline \multirow[t]{2}{*}{ Sexo } & Masculino & 15 & 62,5 & 9 & 36 \\
\hline & Feminino & 9 & 37,5 & 16 & 64 \\
\hline \multirow[t]{4}{*}{ Estado Civil } & Solteiro & 8 & 33,3 & 8 & 32 \\
\hline & Casado & 13 & 64,2 & 15 & 60 \\
\hline & Divorciado & 1 & 4,2 & 2 & 8 \\
\hline & Não respondeu & 2 & 8,3 & - & - \\
\hline \multirow[t]{5}{*}{ Escolaridade } & $\begin{array}{l}\text { Ensino } \\
\text { Completo }\end{array}$ & 1 & 4,2 & 1 & 4 \\
\hline & $2^{\circ}$ Grau Completo & 7 & 29,2 & 2 & 8 \\
\hline & $3^{\circ}$ Grau Incompleto & 6 & 25 & 7 & 28 \\
\hline & $3^{\circ}$ Grau Completo & 7 & 29,2 & 11 & 44 \\
\hline & Pós-Graduação & 2 & 8,3 & 3 & 12 \\
\hline \multirow[t]{7}{*}{ Religião } & Católico & 10 & 41,7 & 9 & 36 \\
\hline & Cristão & 4 & 16,7 & 2 & 8 \\
\hline & Evangélico & 3 & 12,5 & 5 & 20 \\
\hline & Não possui religião & 4 & 16,7 & 2 & 8 \\
\hline & Ecumênico & 1 & 4,2 & 2 & 8 \\
\hline & Espírita & - & - & 1 & 4 \\
\hline & Não respondeu & 2 & 8,3 & 4 & 16 \\
\hline \multirow[t]{3}{*}{ Cargo Exercido } & Policial Militar & 14 & 58,3 & 12 & 48 \\
\hline & Policial Civil & 3 & 12,5 & 8 & 32 \\
\hline & Não policial & 7 & 29,2 & 5 & 20 \\
\hline
\end{tabular}

\section{Instrumentos}

Foi utilizado o Questionário sobre comportamentos do homem $e$ da mulher em relacionamento íntimo de Callou et al. (2016). Adicionou-se uma categoria denominada "Relação do profissional com a vítima" para abarcar a influência do treinamento, a qual continha três itens: "A mulher que denuncia repetidas vezes uma agressão e ainda assim permanece com o 
companheiro, não quer realmente solucionar o problema"; "Quando a mulher quer voltar atrás na denúncia, ela está desvalorizando o trabalho do profissional"; e "Se o companheiro agride apenas verbalmente a mulher não é necessário que ela faça uma denúncia”. Assim, o questionário final era composto por um total de 35 itens, alocados em 12 categorias (Tabela 2). Na parte inicial do questionário, além das informações coletadas sobre idade, sexo, orientação sexual, escolaridade e renda, foram coletadas informações sobre o tipo de cargo exercido e se fizeram ou não algum treinamento sobre violência contra a mulher. Cada item do questionário foi respondido de acordo com uma escala do tipo Likert de quatro pontos: concordo totalmente, concordo parcialmente, discordo parcialmente e discordo totalmente.

Tabela 2

Categorias e Itens do Questionário Sobre os Comportamentos do Homem e da Mulher em Situação de Relacionamento Íntimo

\begin{tabular}{|c|c|}
\hline Categorias & Itens \\
\hline $\begin{array}{l}\text { 1. Papel tradicional feminino e } \\
\text { masculino* }\end{array}$ & $\begin{array}{l}\text { 4. A mulher deve ficar do lado do marido, independentemente da situação. } \\
\text { 5. À mulher cabe se preocupar com a família e a casa, por isso é compreensível que sua carreira seja } \\
\text { menos importante que a do seu marido. } \\
\text { 11. Ao marido cabe a responsabilidade de prover o sustento da família, enquanto a esposa cuida do } \\
\text { lar. } \\
\text { 12. A mulher deve fazer de tudo para fazer o relacionamento dar certo. } \\
\text { 18. Por ser mais frágil, a mulher precisa da proteção do homem. } \\
\text { 19. É esperado que o homem tome partido das coisas, tenha atitude, seja o chefe da família. } \\
\text { 20. O companheiro tem o direito de alertar a sua mulher que determinadas roupas não são adequadas } \\
\text { e impedi-la de usá-las, pois ele deve protegê-la de situações de assédio. }\end{array}$ \\
\hline 2. Privacidade da relação* & $\begin{array}{l}\text { 8. Não se deve interferir quando um casal estiver brigando, melhor deixar que eles se resolvam. } \\
\text { 35. Quando ocorre uma briga com agressão física entre o casal, outras pessoas não devem interferir. }\end{array}$ \\
\hline 3. Modelo de família intacta é o ideal* & $\begin{array}{l}\text { 17. A mulher deve entender que um casamento infeliz é melhor que uma família desfeita, porque nesse } \\
\text { caso os danos seriam piores. } \\
\text { 28. É preferível manter um casamento infeliz a ter uma família desestruturada. }\end{array}$ \\
\hline 4. Responsabilidade da vítima* & $\begin{array}{l}\text { 1. Em alguns casos, a mulher dá motivos para apanhar. } \\
\text { 3. Algumas mulheres só se comportam adequadamente se os companheiros são violentos. } \\
\text { 10. É compreensível que o companheiro se altere e agrida a companheira que se interessa por outros } \\
\text { homens. } \\
\text { 13. Quando a mulher sai sozinha, sabendo que seu companheiro não gosta disso, se torna } \\
\text { compreensível que ele seja violento. } \\
\text { 14. Se a mulher apanha e mesmo assim continua com o companheiro é porque não se importa em } \\
\text { apanhar. } \\
\text { 16. Se a mulher tem muito amigo homem, então não se pode confiar muito. } \\
\text { 23. Se a mulher apronta, deixando seu companheiro irritado, ela tem alguma culpa caso sofra violência } \\
\text { doméstica. } \\
\text { 26. A mulher que apanha e continua com o parceiro gosta de apanhar. }\end{array}$ \\
\hline 5. Ciúme relacionado ao amor* & $\begin{array}{l}\text { 9. É normal ter ciúme quando se ama. } \\
\text { 21. Só sente ciúme aquele que quer proteger a quem ama. } \\
\text { 24. A pessoa está certa em desconfiar se o seu parceiro não demonstra ciúme. }\end{array}$ \\
\hline 6. Ciúme relacionado à violência* & $\begin{array}{l}\text { 6. É natural que o ciúme leve o homem a ser agressivo, porque ele não quer perder a companheira. } \\
\text { 22. Não se pode manter controle sobre suas ações quando se sente ciúme. }\end{array}$ \\
\hline $\begin{array}{l}\text { 7. Atribuição da violência ao } \\
\text { caráter/natureza } \\
\text { internalismo** }\end{array}$ & 2. Depende da natureza do homem ser violento. Alguns são naturalmente agressivos, outros não. \\
\hline 8. Atribuição da violência à educação & 27. Alguns homens são violentos por terem aprendido a ser assim. \\
\hline - aprendizagem** & $\begin{array}{l}\text { 29. Quando uma pessoa vê alguém sendo violento, ela tende a repetir isso, caso se encontre numa } \\
\text { situação semelhante. } \\
\text { 34. É a criação da família que faz com que o homem seja ou não violento. }\end{array}$ \\
\hline $\begin{array}{l}\text { 9. Sexualidade feminina em função da } \\
\text { masculina** }\end{array}$ & $\begin{array}{l}\text { 31. É desnecessário denunciar o homem que pressiona a parceira a ter relações sexuais, pois este é um } \\
\text { dos seus deveres enquanto companheira. } \\
\text { 32. A mulher deve procurar satisfazer sexualmente o companheiro, mesmo quando não está afim, pois } \\
\text { o homem busca fora o que não encontra em casa. }\end{array}$ \\
\hline $\begin{array}{l}\text { 10. Maior tolerância à violência } \\
\text { quando ocorrida verbalmente** } \\
\text { 11. Atribuição da violência ao } \\
\text { consumo do álcool** }\end{array}$ & $\begin{array}{l}\text { 30. Quando ocorre uma briga com agressão apenas verbal entre o casal, outras pessoas não devem } \\
\text { interferir. } \\
\text { 7. Geralmente o homem que bate na mulher está sob efeito do álcool ou outras drogas. }\end{array}$ \\
\hline $\begin{array}{l}\text { 12. Relação do profissional com a } \\
\text { vítima*** }\end{array}$ & $\begin{array}{l}\text { 15. A mulher que denuncia repetidas vezes uma agressão e ainda assim permanece com o companheiro, } \\
\text { não quer realmente solucionar o problema. } \\
\text { 25. Quando a mulher quer voltar atrás na denúncia, ela está desvalorizando o trabalho do profissional. } \\
\text { 33. Se o companheiro agride apenas verbalmente a mulher não é necessário que ela faça uma denúncia. }\end{array}$ \\
\hline
\end{tabular}




\section{Procedimento}

Após a aprovação do projeto de pesquisa pelo Comitê de Ética e Deontologia em Estudos e Pesquisa CEDEP/UNIVASF sob o CAAE 46697015.1.0000.5196, os participantes foram abordados nas instituições (Delegacias, DEAM, CREAS/CRAM e Batalhões de Polícia). Apresentou-se o conteúdo da pesquisa, a relevância da mesma e dispôs-se a assegurar o anonimato dos participantes. Mediante a concordância e assinatura do Termo de Consentimento Livre e Esclarecido - TCLE, os participantes receberam instruções e responderam ao questionário.

\section{Análise de Dados}

Os dados obtidos foram analisados quantitativamente por meio de análises descritivas de percentual e frequência. Também foram verificadas as correlações entre as variáveis ordinais e comparações entre os grupos CT e ST quanto à concordância com as categorias. Para tanto, utilizou-se os testes não-paramétricos de Spearman e Mann-Whitney.

\section{Resultados}

De uma forma geral, houve baixo nível de concordância para ambos os grupos de participantes com e sem treinamento. A comparação entre os grupos CT e ST em termos de concordância apontou apenas uma diferença estatisticamente significativa na categoria 12 (Relacionamento do profissional com a vítima), na qual o grupo CT apresentou maior discordância do que o grupo ST ( $p=0,028)$. É importante mencionar que no grupo CT, nenhuma diferença foi percebida em função da idade, escolaridade e gênero, em relação à categoria 12, demonstrando que a diferença no nível de concordância entre os grupos CT e ST esteve de fato, nessa amostra, associada a ter participado de treinamento sobre violência de gênero.

A Tabela 3 ilustra os níveis de concordâncias parciais e totais e discordâncias parciais e totais com as categorias. Os níveis de concordância total em cada categoria foram relativamente baixos para ambos os grupos, menos que $13 \%$. O grupo CT apresentou concordância total maior em relação à categoria 7 (Atribuição da violência ao caráter/internalismo) (12,5\%) que o grupo ST $(4,2 \%)$ e ambos CT e ST apresentaram uma concordância parcial alta em relação à categoria 8 (Atribuição da violência à educação/aprendizagem) (CT: 23,8\% e ST: 21,7\%).

O grupo ST obteve uma maior concordância total referente à categoria 10 (Maior tolerância à violência quando ocorrida verbalmente) $(11,1 \%)$ que o grupo $\mathrm{CT}(4,4 \%)$, porém a concordância parcial nessa categoria foi maior no grupo CT (CT: 26,7\% e ST: 15,6\%).

Uma diferença acentuada em relação aos níveis de concordância total é encontrada em relação à categoria 11 (Atribuição da violência ao álcool), em que o grupo CT obteve $0 \%$ e o grupo ST, de 10,4\%. E observa-se que a concordância parcial foi maior no grupo CT (CT: 20,8\% e ST: $12,5 \%)$. Isso sugere que o treinamento surtiu algum efeito na redução da concordância total em relação à questão, entretanto, seria interessante observar se os treinamentos ofertados abordaram o uso de substâncias, o que não foi realizado no presente estudo. 
Tabela 3

Média, Desvio padrão e Percentual de Concordância com as Categorias para os grupos CT e ST $(n=49)$.

\begin{tabular}{|c|c|c|c|c|c|c|c|}
\hline Categorias & Grupos & $M$ & $D P$ & $\begin{array}{l}\text { Discordo } \\
\text { Totalmente }\end{array}$ & $\begin{array}{l}\text { Discordo } \\
\text { Parcialmente }\end{array}$ & $\begin{array}{l}\text { Concordo } \\
\text { Parcialmente }\end{array}$ & $\begin{array}{l}\text { Concordo } \\
\text { Totalmente }\end{array}$ \\
\hline \multirow{2}{*}{$\begin{array}{l}\text { 1.Papel tradicional } \\
\text { feminino } \\
\text { masculino }\end{array}$} & $\mathrm{CT}$ & 1,72 & 0,93 & $30,4 \%$ & $7,6 \%$ & $10,2 \%$ & $2,9 \%$ \\
\hline & ST & 1,94 & 1,06 & $24,6 \%$ & $7,0 \%$ & $12,9 \%$ & $4,4 \%$ \\
\hline \multirow{2}{*}{$\begin{array}{l}\text { 2.Privacidade } \\
\text { relação }\end{array}$} & $\mathrm{CT}$ & 1,50 & 0,82 & $35,4 \%$ & $7,3 \%$ & $9,4 \%$ & $0,0 \%$ \\
\hline & ST & 1,76 & 0,97 & $27,1 \%$ & $7,3 \%$ & $11,5 \%$ & $2,1 \%$ \\
\hline \multirow{2}{*}{$\begin{array}{l}\text { 3.Modelo de família } \\
\text { intacta é o ideal }\end{array}$} & $\mathrm{CT}$ & 1,36 & 1,05 & $41,2 \%$ & $3,1 \%$ & $6,2 \%$ & $1,0 \%$ \\
\hline & ST & 1,36 & 0,67 & $36,1 \%$ & $7,2 \%$ & $5,2 \%$ & $0,0 \%$ \\
\hline \multirow{2}{*}{$\begin{array}{l}\text { 4.Responsabilidade } \\
\text { da vítima }\end{array}$} & $\mathrm{CT}$ & 1,39 & 0,55 & $38,2 \%$ & $6,2 \%$ & $6,2 \%$ & $0,5 \%$ \\
\hline & ST & 1,49 & 0,81 & $34,1 \%$ & $6,4 \%$ & $7,7 \%$ & $0,8 \%$ \\
\hline \multirow{2}{*}{$\begin{array}{l}\text { 5.Ciúme relacionado } \\
\text { ao amor }\end{array}$} & $\mathrm{CT}$ & 1,65 & 0,99 & $31,7 \%$ & $6,9 \%$ & $12,4 \%$ & $0,7 \%$ \\
\hline & ST & 1,96 & 0,97 & $20,7 \%$ & $11,7 \%$ & $13,1 \%$ & $2,8 \%$ \\
\hline \multirow{2}{*}{$\begin{array}{l}\text { 6.Ciúme relacionado } \\
\text { à violência }\end{array}$} & $\mathrm{CT}$ & 1,45 & 1,24 & $36,1 \%$ & $7,2 \%$ & $6,2 \%$ & $1,0 \%$ \\
\hline & ST & 1,52 & 0,80 & $33,0 \%$ & $7,2 \%$ & $9,3 \%$ & $0,0 \%$ \\
\hline \multirow{2}{*}{$\begin{array}{lr}\text { 7.Atribuição } & \text { da } \\
\text { violência } & \text { ao } \\
\text { caráter/natureza } & \text { do } \\
\text { homem/internalismo. }\end{array}$} & $\mathrm{CT}$ & 2,33 & 0,79 & $18,8 \%$ & $8,3 \%$ & $10,4 \%$ & $12,5 \%$ \\
\hline & ST & 1,96 & 1,00 & $20,8 \%$ & $14,6 \%$ & $10,4 \%$ & $4,2 \%$ \\
\hline \multirow{2}{*}{$\begin{array}{l}\text { 8.Atribuição da } \\
\text { violência à educação } \\
\text { - Aprendizagem. }\end{array}$} & $\mathrm{CT}$ & 2,21 & 0,89 & $18,2 \%$ & $7,7 \%$ & $23,8 \%$ & $2,8 \%$ \\
\hline & ST & 2,13 & 1,02 & $19,6 \%$ & $4,2 \%$ & $21,7 \%$ & $2,1 \%$ \\
\hline \multirow{2}{*}{$\begin{array}{l}\text { 9. Sexualidade } \\
\text { feminina em função } \\
\text { da masculina. }\end{array}$} & $\mathrm{CT}$ & 1,16 & 0,74 & $47,9 \%$ & $3,2 \%$ & $1,1 \%$ & $1,1 \%$ \\
\hline & ST & 1,30 & 0,67 & $38,3 \%$ & $3,2 \%$ & $5,3 \%$ & $0,0 \%$ \\
\hline \multirow{2}{*}{$\begin{array}{l}\text { 10.Maior tolerância à } \\
\text { violência quando } \\
\text { ocorrida } \\
\text { verbalmente. }\end{array}$} & $\mathrm{CT}$ & 2,33 & 0,78 & $17,8 \%$ & $4,4 \%$ & $26,7 \%$ & $4,4 \%$ \\
\hline & ST & 2,62 & 1,07 & $8,9 \%$ & $11,1 \%$ & $15,6 \%$ & $11,1 \%$ \\
\hline \multirow{2}{*}{$\begin{array}{l}\text { 11.Atribuição da } \\
\text { violência ao } \\
\text { consumo do álcool. }\end{array}$} & $\mathrm{CT}$ & 2,17 & 0,79 & $12,5 \%$ & $16,7 \%$ & $20,8 \%$ & $0,0 \%$ \\
\hline & $\mathrm{ST}$ & 2,38 & 1,13 & $14,6 \%$ & $12,5 \%$ & $12,5 \%$ & $10,4 \%$ \\
\hline \multirow{2}{*}{$\begin{array}{l}\text { 12.Relação do } \\
\text { profissional com a } \\
\text { vítima. }\end{array}$} & $\mathrm{CT}$ & 1,71 & 0,97 & $29,0 \%$ & $11,7 \%$ & $8,3 \%$ & $2,8 \%$ \\
\hline & ST & 2,13 & 1,02 & $17,2 \%$ & $12,4 \%$ & $13,8 \%$ & $4,8 \%$ \\
\hline
\end{tabular}

No grupo ST, houve diferenças no nível de concordância em função das variáveis idade, escolaridade e gênero. Quanto à idade, foi verificado que os participantes com maior idade apresentaram menor nível de concordância com as regras que apontavam uma natureza violenta do homem (categoria 7), uma vez que foi verificada a partir do teste de Spearman uma correlação negativa moderada $(-0,470 ; p=0,02)$. O mesmo tipo de correlação inversa, porém, com maior 
força, foi verificada entre a idade e maior tolerância à violência quando ocorrida verbalmente (categoria $10 ;-0,632 ; p=0,002$ ). Ainda no grupo ST, foi verificado que participantes com maior escolaridade tendem a concordar menos com a ideia da sexualidade feminina em função da masculina (categoria 9) com uma correlação de força moderada $(-0445 ; p=0,043)$.

Em relação ao gênero, os homens apresentaram níveis de concordância maiores na categoria 5 (Associação entre amor e ciúme) do que as mulheres. Isso ocorreu tanto no grupo CT, com médias de 2,07 e 1,41 ( $p<0,05)$, quanto no grupo ST, com médias de 2,19 e 1,54 $(p<0,05)$ para homens e mulheres, respectivamente.

\section{Discussão}

Assim como no estudo de Callou et al. (2016) e Gomes e Costa (2014), foram encontradas baixos índices de concordância para ambos os grupos de participantes com e sem treinamento. Os baixos índices eram esperados, também pelo fato de se tratar de uma amostra composta por profissionais que trabalham com violência (Machado et al., 2009).

Com relação à maior discordância na categoria 12 (Relacionamento do profissional com a vítima) do grupo CT, é necessário frisar, entretanto, que uma limitação importante do presente estudo foi a falta de acesso ao tipo de treinamento que os participantes fizeram, tendo em vista que foi considerado apenas o relato do participante sobre a realização de treinamento sobre violência contra a mulher. Além disso, também há limitações na extrapolação dos achados para a postura dos profissionais em seu cotidiano de atuação, especialmente quando a diferença entre os grupos ocorreu somente na categoria relacionada à atuação profissional. Contudo, observa-se que, independentemente do tipo de treinamento, houve pelo menos alteração no relato, evidenciado aqui em termos de concordância com as regras. Assim, treinamentos sobre violência de gênero para profissionais parecem modificar a concordância com os itens relativos à prática profissional e relação com a vítima, porém sem alterações nas demais categorias.

A concordância total maior no grupo CT em relação à categoria 7 (Atribuição da violência ao caráter/internalismo) sugere que o treinamento pode ter favorecido uma compreensão da violência como decorrente de causas internas (e.g., personalidade e caráter) sem, porém, desconsiderar a aprendizagem. Um dado que sugere uma visão contextualizada do fenômeno da violência é a maior concordância parcial em ambos os grupos na categoria 8 (Atribuição da violência à educação/aprendizagem), a qual sugere a relação entre sujeito e ambiente como fundamento para a construção de um comportamento violento. Essa visão interacionista é defendida pela análise do comportamento, onde o comportamento do sujeito é modelado a partir de sua interação com o seu ambiente. Os comportamentos, inclusive os violentos, não são oriundos de uma "natureza humana", mas sim aprendidos pelos sujeitos a partir de sua interação com o seu ambiente social e mantidos pelas consequências produzidas por essa interação (Skinner, 1957/1978).

A maior discordância total e concordância parcial na categoria 10 (Maior tolerância à violência quando ocorrida verbalmente) no grupo CT aponta que, apesar do aumento na discordância total, ainda há uma tolerância maior quando o abuso é verbal, mesmo após treinamento. Isso levanta uma questão preocupante que vem sendo apontada pela literatura que é a dificuldade em identificar a violência psicológica (Silva, Coelho \& Caponi, 2007). A Política Nacional de Enfrentamento à Violência contra as Mulheres (Brasil, 2011) define violência psicológica como toda ação ou omissão que venha a causar dano à autoestima, à identidade ou ao desenvolvimento da pessoa, incluindo ameaças, depreciação, humilhação, chantagem, dentre outras.

A ausência de concordância total na categoria 11 (Atribuição da violência ao álcool) e maior concordância parcial nessa categoria no grupo CT indica que os profissionais com treinamento não atribuíram a violência somente ou diretamente ao álcool, no entanto não 
menosprezaram os seus efeitos na violência doméstica, como sugere o seguinte comentário P49(CT): "As substâncias psicoativas trazem consequências danosas para a relação familiar, mas não é o único fator (sic)". Estudos (Signori \& Madureira, 2007; Vieira et al., 2009) apontam que os profissionais de segurança relatam o álcool entre os motivos principais de violência e que em uma grande parcela dos casos em que atuaram, o álcool estava presente. Isso aparece também em outros comentários: P45(ST): "Álcool e drogas potencializam o crime. O dia-a-dia da delegacia revela que na maioria das ocorrências o homem estava sob efeito de álcool ou droga (sic)."; P10(ST): "Em minha experiência policial, todos os agressores estavam sob efeito do álcool (sic)". De fato, o uso do álcool esteve envolvido em 56,6\% das denúncias registradas em 325 inquéritos da DEAM de Fortaleza avaliados por Gama, Filho, Silva, Vieira e Parente (2014). Uma revisão realizada por Oliveira et al. (2017) também indica que o ciúme, a ingestão de álcool e o uso de outras drogas são as principais causas da violência contra a mulher. Porém, o estudo de Medeiros (2015) aponta que fatores comportamentais relacionados ao agressor são fatores de risco mais fortes que o padrão de uso de álcool e drogas.

Como já mencionado, as similaridades quanto à idade, escolaridade e gênero no grupo CT em relação à categoria 12 (Relacionamento do profissional com a vítima) aponta que a variável responsável pela diferença de concordância entre os grupos CT e ST nessa categoria é o treinamento. É interessante observar que muito embora essa diferença tenha ocorrido na Categoria 12, ela não se estendeu para as outras categorias aqui analisadas. Considerando os itens da categoria 12, as respostas dos profissionais parecem valorizar a denúncia prestada pela usuária, independente se ela continuará com o agressor e o denunciará várias vezes e ainda se a mulher decide, posteriormente, retirar a queixa contra o companheiro. O grupo CT também parece ser "menos tolerante" às agressões verbais, para as quais defendem o recurso da denúncia. Porém, é necessária uma avaliação do treinamento e das modificações geradas por ele nas concepções de gênero e nos diversos fatores relativos à violência contra a mulher para que se verifique o alcance concreto do treinamento nas concepções de gênero do profissional e em sua atuação.

No grupo ST, as correlações negativas entre idade, por um lado, e concordância com uma natureza violenta do homem (categoria 7) e maior tolerância à violência quando ocorrida verbalmente (categoria 10), por outro, sugerem que nesse grupo os participantes de maior idade tendiam a atribuir a violência a outros fatores não "naturais", como aprendizagem e cultura, além de serem menos tolerantes à violência verbal. Isso sugere um efeito conjunto de outras variáveis que possivelmente acompanham a idade, como mais experiência relacional e profissional. Seria interessante investigar se a experiência profissional reduz a atribuição da violência a fatores internos. Porém, no presente trabalho, não foi verificado tempo de atuação profissional, o que aponta para a necessidade de estudos futuros. Nesse sentido, outra correlação negativa encontrada nesse grupo, também quanto à variável idade mas agora com a ideia da sexualidade feminina em função da masculina (categoria 9), corrobora com os dados encontrados na literatura em relação ao maior nível de escolaridade e menor concordância com esse tipo de regra (Callou et al., 2016; Gomes \& Costa, 2014) e ainda em termos de menor nível instrucional dentre aqueles que praticam a violência (Silva et al., 2015).

A maior concordância entre os homens com a categoria 5 (Associação entre amor e ciúme) indica que as mulheres, diferentemente dos homens, podem compreender o comportamento ciumento como sendo diferente do comportamento afetuoso/amoroso (Sucre \& Petrizzo, 2016). É interessante considerar que Costa (2016) encontrou associação entre sentimento de posse e violência sexual no discurso de mulheres vítimas de violência. Além disso, essa dissociação entre ciúme e amor parece ainda mais necessária diante de evidências de que o ciúme pode atuar de forma a amenizar a percepção pejorativa que a violência contra a mulher provoca em participantes americanos (Puente \& Cohen, 2003) e brasileiros (Costa et al., 2016), o que sugere um aspecto cultural em comum. Em termos funcionais, o ciúme ocorre em uma situação de competição por reforçadores na presença de um rival e pode ser mantido por consequências sociais (atenção) ou 
pelo afastamento do rival, sendo, portanto, passível de extinção (Oliveira \& Paranaguá, 2017). Essa compreensão é importante para os profissionais que trabalham com violência, pois além de uma provável redução da tolerância para o comportamento ciumento, fornece uma nova possibilidade de análise.

Considerados em conjunto, estes dados apontam para a importância do treinamento de profissionais nestes espaços e a necessidade de analisar e revisar as práticas institucionais de serviços de atendimento à vítima de violência doméstica no Brasil (Abdala, Silveira \& Minayo, 2011; Brandão, 2006; Hasse \& Vieira, 2014; Santos, 2008), principalmente diante da evidência de que um dos fatores de risco para a violência física contra a mulher é a recidiva de agressão sem registro de denúncia (Gama et al., 2014). A responsabilização e culpabilização da vítima, por exemplo, é um grande problema no atendimento realizado por profissionais de saúde (Souza \& Cintra, 2018). Estudos desse tipo garantiriam um melhor funcionamento dessas instituições e do serviço oferecido, com o objetivo de proporcionar o desenvolvimento das competências necessárias aos profissionais para aprimorar, além dos trâmites jurídicos, a mediação dos conflitos e a afirmação dos direitos fundamentais da vítima (Nobre \& Barreira, 2008).

Apesar da quantidade limitada de participantes do presente estudo, os dados foram relevantes para a compreensão do processo de formação dos profissionais na região, oferecendo uma perspectiva de análise das regras com as quais esses profissionais tendem ou não a concordar. Para estudos futuros, sugere-se uma amostra maior, que permita o uso de testes estatísticos paramétricos e uma análise conjunta da interação entre diversas variáveis (escolaridade, idade, sexo, categoria profissional). Esses estudos também favoreceriam a generalização dos resultados. Sugere-se também um melhor controle sobre o tipo de treinamento ao qual o participante foi submetido. O treinamento poderia ser melhor caracterizado em termos de duração da formação, conteúdo programático, estratégias metodológicas e tempo decorrido entre o treinamento e a realização da pesquisa.

\section{Referências}

Abdala, C., Silveira, K. \& Minayo, M. C. S. (2011). Aplicação da Lei Maria da Penha nas delegacias de mulheres: O caso do Rio de Janeiro. DILEMAS: Revista de Estudos de Conflito e Controle Social, 4(4), 571-600.

Aguiar, J. M. \& d'Oliveira A. F. P. L. (2011). Violência institucional em maternidades públicas sob a ótica das usuárias. Interface: Comunicação, Saúde, Educação, 15, 79-92. doi: 10.1590/S141432832010005000035

Albuquerque, L. C., Mescouto, W. A. \& Paracampo, C. C. P. (2010). Controle por regras: efeitos de perguntas, sugestões e ordens. Acta Comportamentalia, 19(1), 19-42.

Bandeira, L. M. (2014). Violência de gênero: a construção de um campo teórico e de investigação. Revista Sociedade e Estado, 29(2), 449-469. doi: 10.1590/S0102-69922014000200008

Barros, C. R. S., \& Schraiber, L. B. (2017). Violência por parceiro íntimo no relato de mulheres e homens usuários de unidades básicas. Revista de Saúde Pública, 51-57. doi: 10.1590/S15188787.2017051006385

Baum, W. M. (2005/2006). Compreender o behaviorismo: comportamento, cultura e evolução. Porto Alegre: Artmed.

Brandão, E. R. (2006). Renunciantes de Direitos? A Problemática do enfrentamento público da violência contra a mulher: o caso da Delegacia da Mulher. PHYSIS: Revista de Saúde Coletiva, 16(2), 207-231. doi: 10.1590/S0103-73312006000200005.

Brasil (2011). Politica Nacional de Enfrentamento à Violência Contra as Mulheres. Secretaria de Políticas para as Mulheres. Brasília. Recuperado de http://spm.gov.br/publicacoesteste/publicacoes/2011/politica-nacional/view

Brigadão, J. I. M., Santos, F. B. P., \& Spink, P. K. (2016). A sustentabilidade e a continuidade de redes de articulação: o caso do Iluminar Campinas. Saúde e Sociedade, 25, 361-368. doi: 10.1590/S010412902016143671. 
Callou, I. C, Bastos, T., Moreira, J. M. \& Souza, J. M. (2016). Regras descritivas ocidentais e violência contra a mulher por parceiro íntimo. Acta comportamentalia, 24(1), 79-94.

Cavalcanti, L. F., Moreira, G. A. R., Vieira, L. J. E. S., \& Silva, R. M. (2015). Implementação da atenção em saúde às violências sexuais contra as mulheres em duas capitais brasileiras. Saúde Debate, 39, 1079-1091. doi: 10.1590/0103-110420151070381

Costa, A. V. M. (2016). Saberes e atitudes de mulheres sobre a violência contra a mulher pelo parceiro íntimo (Dissertação de mestrado não publicada). Universidade Federal do Piauí, Teresina, PI. Recuperado de https://repositorio.ufpi.br/xmlui/handle/123456789/1014

Costa, N., Gomes, H., Almeida, T., Pinheiro, R. S., Almeida, C., Gondim, L., Silva, M., Campos, R. S., Silva, S. M., \& Lima, V. (2016). Violence against women: Can "jealousy" mitigate the significance of violence? Estudos de Psicologia - Campinas, 33, 525-533. doi: 10.1590/1982-02752016000300015

Coronel, A. L. C., \& Silva, H. T. H. (2018). Interrelation between functional constipation and domestic violence. Journal of Coloproctology, 38, 117-123. doi: 10.1016/j.jcol.2017.12.003

Del Prette, Z. A. P. \& Del Prette, A. (2011). Habilidades sociais: Intervenções efetivas em grupo. São Paulo: Casa do Psicólogo.

Gama, I. S., Filho, J. G. B., Silva, J. G., Vieira L. J. E. S., \& Parente, E. O. (2014). Fatores associados à violência física denunciada por mulheres. Journal of Health and Biological Science, 2, 168-175. doi: 10.12662/2317-3076jhbs.v2i4.105.p168-175.2014

Gomes, B. C. G. (2015). Crítica à aplicação da lei 11.340/2006: Um estudo sobre a eficácia da Lei Maria da Penha sobre o prisma da pesquisa elaborada pelo Instituto de Políticas Econômicas Aplicadas. Revista da Faculdade de Direito de São Bernardo do Campo, 2, 1-15.

Gomes, H. C. R. \& Costa, N. (2014). Violência contra a mulher: uma pesquisa empírica sobre regras descritivas comuns na sociedade ocidental. Acta Comportamentalia, 22(1), 89-100.

Hasse, M., \& Vieira, E. M. (2014). Como os profissionais de saúde atendem mulheres em situação de violência? Uma análise triangulada de dados. Saúde Debate, 38, 482-493. doi: 10.5935/01031104.20140045

Invisível aos olhos: a violência institucional da tortura contra mulheres (2015). Recuperado de http://justificando.cartacapital.com.br/2015/11/27/invisivel-aos-olhos-a-violencia-institucional-datortura-contra-mulheres/

IPEA revela dados inéditos sobre violência contra a mulher (2013). Recuperado de: http://www.ipea.gov.br/portal/index.php?option=com_content\&id=19873

Juíza pergunta a vítima de estupro se ela "tentou fechar as pernas" (2016). O Globo. Recuperado de http://oglobo.globo.com/sociedade/juiza-pergunta-vitima-de-estupro-se-ela-tentou-fechar-as-pernas18843567

Lindner, S. R., Coelho, E. B. S., Bolsoni, C. C., Rojas, P. F., \& Boing, A. F. (2015). Prevalence of intimate partner physical violence in men and women from Florianópolis, Santa Catarina State, Brazil: a population-based study. Cadernos de Saúde Pública, 31, 815-826. doi: 10.1590/0102-311x00159913

Machado, C., Matos, M., Saavedra, R. M., Cruz, O. F. S., Antunes, C. M. V., Pereira, M., Rato, A., Pereira, I., Carvalho, C. \& Capitão, L. (2009). Crenças e atitudes dos profissionais face à violência conjugal: estudos com profissionais de saúde, polícias e professores. Acta Médica Portuguesa, 22 (6), 735-742.

Mapeamento das Delegacias da Mulher no Brasil (2008). Recuperado de http://www.observatorioseguranca.org/pdf/MAPEO_Brasil\%5B1\%5D.pdf

Matos, M. A. (2001) Comportamento Governado por Regras. Revista Brasileira de Terapia Comportamental e Cognitiva, 3, 51-66. doi: 10.31505/rbtcc.v3i2.135

Mattos, P. R., Ribeiro, I. S., \& Carmago, V. C. (2012). Análise dos Casos Notificados de Violência Contra Mulher. Cogitare Enferm, 17(4), 738-44. doi: 10.5380/ce.v17i4.30383

Medeiros, M. N. (2015). Avaliação de risco em casos de violência contra a mulher perpetrada por parceiro íntimo (Tese de doutorado não publicada). Universidade de Brasília, Brasília, DF. Recuperado de: https://repositorio.unb.br/handle/10482/20191

Mota, J. G. (2004). Violência contra a mulher praticada pelo parceiro íntimo: Estudo em um serviço de atenção especializado. (Dissertação de Mestrado não publicada). Fundação Oswaldo Cruz, Rio de Janeiro, RJ. Recuperado de: https://www.arca.fiocruz.br/handle/icict/4914

Nobre, M. T. \& Barreira, C. (2008). Controle Social e Mediação de Conflitos: as delegacias da mulher e a violência doméstica. Sociologias, 10(20), 138-163. doi: 10.1590/S1517-45222008000200007 
Oliveira, I. J. S. O., \& Paranaguá, M. P. N. (2017). Amor e ciúme psicopatológico: uma visão fundamentada na perspectiva analítico-comportamental. Fragmentos de Cultura, 27, 555-569. doi: 10.18224/frag.v27i4.5758

Oliveira, F. S., Araújo, L. M., Silva, L. L., Crispim, Z. M., Lucindo, V. B. D. B., \& Oliveira, L. N. (2017). Violência doméstica e sexual contra a mulher: revisão integrativa. Holos, 8, 275-284. doi: 10.15628/holos.2017.1903

Operação Ronda Maria da Penha chega a Juazeiro (2015). Recuperado de http://www.secom.ba.gov.br/2015/11/129351/ Operacao-Ronda-Maria-da-Penha-chega-aJuazeiro.html

Organização Mundial da Saúde (2014). Relatório Mundial Sobre a Prevenção da Violência. 2014. Recuperado em 14 de agosto de 2020 de: http://apps.who.int/iris/bitstream/10665/145087/15/WHO_NMH_NVI_14.2_por.pdf

Paracampo, C. C. P., Albuquerque, L. C., Carvalló, B. N., \& Torres, S. M. (2009). Análise do controle por regras apresentadas em histórias infantis. Revista Brasileira de Análise do Comportamento, 5, 107122. doi: $10.18542 /$ rebac.v5i2.933

Pedrosa, C. M., \& Spink, M. J. P. (2011). A violência contra a mulher no cotidiano dos serviços de saúde: desafios para a formação médica. Saúde e Sociedade, 20, 124-135. doi: 10.1590/S010412902011000100015

Pereira, M. T. L. N. (2006). Resistências femininas e ação policial: (re)pens ando a função social das delegacias da mulher (Tese de doutorado não publicada). Universidade Federal do Ceará, Fortaleza, CE. Recuperado de: http://www.repositorio.ufc.br/handle/riufc/1525

Puente, S., \& Cohen, D. (2003). Jealousy and meaning (or nomeaning) of violence. Personality and Social Psychology Bulletin, 29, 449-460. doi: 10.1177/0146167202250912

Rosa, L. W., \& Falcke, D. (2014). Violência conjugal: compreendendo o fenômeno. Revista da SPAGESP, $15,17-32$.

Ruiz, M. (2003). Inconspicuous Sources of Behavioral Control: The Case of Gendered Practices. The Behavior Analyst Today, 4(1), 12-16. doi: 10.1037/h0100005

Saffioti, H. I. B. (2001). Contribuições feministas para o estudo de violência de gênero. Cadernos Pagu, $16,115-136$.

Sant' Ana, V. L. P. (2003). Identidade sexual e identidade de gênero. Em: M. Z. da S. Brandão, F. C. de S. Conte, F. S. Brandão, Y. K. Ingberman, C. B. de Moura, V. M. da Silva, \& S. M. Oliane (Orgs). Sobre comportamento e cognição: clínica pesquisa e aplicação (pp. 154-161) v. 12. Santo André, SP: Esetec Editores Associados.

Santos, C. M. (2008). Da delegacia da mulher à Lei Maria Da Penha: lutas feministas e políticas públicas sobre violência contra mulheres no Brasil. Oficina do Centro de Estudos Sociais, 301. Recuperado de https://ces.uc.pt/publicacoes/oficina/ficheiros/301.pdf

Santos, T. P. S., Antunes, T. C. S., \& Penna, L. H. G. (2014). Perfil sociocultural de mulheres que vivenciaram violência sexual em uma unidade hospitalar de referência. Journal of Research: Fundamental Care, 6, 1445-1454. doi: 10.9789/2175-5361.2014.v6i4.1445-1454

Schlinger, H., \& Blakely, E. (1987). Function-altering effects of contingency-specifying stimuli. The Behavior Analyst, 10, 41-45. doi: 10.1007/BF03392405

Scott, J. W. (1986). Gender: A useful category of historical analysis. The American Historical Review, 91(5), 1053-1075.

Secretaria Especial de Políticas para as Mulheres (2006). Norma Técnica de Uniformização Centros de Referência de Atendimento à Mulher em Situação de Violência. Recuperado de http://www.spm.gov.br/sobre/a-secretaria/subsecretaria-de-enfrentamento-a-violencia-contra-asmulheres/pacto/documentos/norma-tecnica-centros-de-referencia.pdf.

Sidman, M. (1989/2003). Coerção e suas implicações. Campinas: Livro Pleno.

Signori, M. \& Madureira, V. S. F. (2007). A violência contra a mulher na perspectiva de policiais militares: espaço para a promoção da saúde. para a promoção da saúde. Acta Scientiarum. Health Sciences, 29(1), 7-18. doi: 10.4025/actascihealthsci.v29i1.100

Silva, E. C. \& Laurenti, C. (2016). B. F. Skinner e Simone de Beauvoir: "a mulher" à luz do modelo de seleção pelas consequências. Revista Perspectivas, 7(2), 197-211. doi: 10.18761/pac.2016.009 
Silva, J. N., Sousa, R. A., \& Borges, M. A. (2015). Violência doméstica: análise e correlações do perfil educacional de autores e vítimas na cidade de arraias nos anos de 2012 e 2014. Revista Observatório, 1, 294-316. doi: 10.20873/uft.2447-4266.2015v1n3p294

Silva, L. L., Coelho, E. B. S. \& Caponi, S. N. C. (2007). Violência silenciosa: violência psicológica como condição da violência física doméstica. Interface: Comunicação, Saúde, Educação, 11(21), 93-103. doi: 10.1590/S1414-32832007000100009.

Skinner, B. F. (1957/1978). O Comportamento Verbal. São Paulo: Cultrix, EDUSP.

Sousa, M. D. C. M. (2014). Quanto custa o machismo? Uma análise das ações interventivas realizadas pelo Serviço Social Previdenciário junto ao Centro de Referência Estadual da Mulher - Fátima Lopes no município de Campina Grande - PB (Trabalho de Conclusão de Curso não publicado). Universidade Estadual da Paraíba, Campina Grande, Paraíba. Recuperado de: http://dspace.bc.uepb.edu.br/jspui/handle/123456789/8382

Souza, A. A. C., \& Cintra, R. B. (2018). Conflitos éticos e limitações do atendimento médico à mulher vítima de violência de gênero. Revista Bioética, 26, 77-86. doi: 10.1590/1983-80422018261228

Sucre, S. P. A., \& Petrizzo, A. G. (2016). Amor, familia y violência: construcciones sociales de mujeres maltratadas por sus parejas y que transitan por el processo legal correspondiente. Analogías del Comportamiento, 14, 83-105.

Taquette, S. R. (2015). Violência contra a mulher adolescente - revisão de estudos epidemiológicos brasileiros publicados entre 2006 e 2011. Adolescência e Saúde, 12, 66-77.

Tavares, M. S. (2016). Violência contra as mulheres e acesso à justiça: notas sobre uma roda de conversa em Itinga/BA. Revista Feminismos, 4, 132-140.

Vieira, E. M., Persona, G. C. S, Almeida, A. M., Santos, M. A. Daltoso, D., \& de Ferrante, F. G. (2009). Conhecimento e atitudes dos profissionais de saúde em relação à violência de gênero. Revista Brasileira de Epidemiologia, 12(4), 566-577. doi: 10.1590/S1415-790X2009000400007.

Waiselfisz, J. J. (2015). Mapa da Violência 2015: Homicídios de mulheres no Brasil. Brasília, DF. Recuperado de: http://www.mapadaviolencia.org.br/pdf2015/MapaViolencia_2015_mulheres.pdf

Participação dos autores: a) Planejamento e concepção do trabalho; b) Coleta de dados; c) Análise e interpretação de dados; d) Redação do manuscrito; e) Revisão crítica do manuscrito.

J.M.M. contribuiu em a,b,c,d,e; H.L.S.P. em a,b,c,d; G.O.C. em c,d,e; J.M.S. em c,d,e.

Editora científica responsável: Dra. Cecilia Cracco 